\title{
Article
}

\section{First-Trimester Screening for Gestational Diabetes Mellitus in Twin Pregnancies}

\author{
Olga Buerger ${ }^{1}$, Tania Elger ${ }^{1}$, Antonia Varthaliti ${ }^{1}$, Argyro Syngelaki ${ }^{1}$, Alan Wright ${ }^{2}$ and Kypros H. Nicolaides ${ }^{1, *}$ \\ 1 Fetal Medicine Research Institute, King's College Hospital, London SE5 8BB, UK; olga.buerger@nhs.net (O.B.); \\ tania.elger@nhs.net (T.E.); antonia.varthaliti@nhs.net (A.V.); argyro.syngelaki@nhs.net (A.S.) \\ 2 Institute of Health Research, University of Exeter, Exeter EX4 4QG, UK; alan@dw-stats.co.uk \\ * Correspondence: kypros@fetalmedicine.com; Tel.: +44-20-3299-8256; Fax: +44-20-7733-9534
}

Citation: Buerger, O.; Elger, T.; Varthaliti, A.; Syngelaki, A.; Wright, A.; Nicolaides, K.H. First-Trimester Screening for Gestational Diabetes Mellitus in Twin Pregnancies. J. Clin. Med. 2021, 10, 3814. https://doi.org/10.3390/ jcm10173814

Academic Editor: Eyal Sheiner

Received: 26 July 2021

Accepted: 23 August 2021

Published: 25 August 2021

Publisher's Note: MDPI stays neutral with regard to jurisdictional claims in published maps and institutional affiliations.

Copyright: (c) 2021 by the authors. Licensee MDPI, Basel, Switzerland. This article is an open access article distributed under the terms and conditions of the Creative Commons Attribution (CC BY) license (https:// creativecommons.org/licenses/by/ $4.0 /)$.

\begin{abstract}
We previously reported a logistic regression model for prediction of GDM from maternal characteristics and medical history in 75,161 singleton pregnancies. In this study of 1376 twin and 13,760 singleton pregnancies recruited at 11-13 weeks' gestation, we extend the model to include terms for twin pregnancies. We found the respective odds of GDM in dichorionic and monochorionic twin pregnancies to be 1.36 (95\% CI: 1.02-1.81) and 2.78 (95\% CI: 1.72-4.48) times higher than in singleton pregnancies. In both singleton and twin pregnancies, the risk for GDM increased with maternal age and weight and birth weight z-score of a baby in a previous pregnancy and is higher in women with a previous pregnancy complicated by GDM; in those with a first- or second-degree relative with diabetes mellitus; in women of Black, East Asian, and South Asian racial origin; and in pregnancies conceived through the use of ovulation-induction drugs. In singleton pregnancies, at $10 \%$ and $20 \%$ false-positive rate, the detection rate was $43 \%$ and $58 \%$, respectively. In twin pregnancies, using risk cut-offs corresponding to $10 \%$ and $20 \%$ false-positive rates in singletons, the respective false-positive rates were $27 \%$ and $47 \%$, and the detection rates were $63 \%$ and $81 \%$.
\end{abstract}

Keywords: first trimester screening; pyramid of prenatal care; gestational diabetes mellitus; twin pregnancies

\section{Introduction}

Gestational diabetes mellitus (GDM) is associated with a plethora of complications for both mother and baby in short and long term [1-6]. The diagnosis of GDM relies on a positive oral glucose tolerance test, which can be performed either universally to all pregnant women [7] or selectively depending on certain risk factors from demographic characteristics and obstetric history [8]. In a previous study of 75,161 singleton pregnancies, we developed a screening model for GDM by combining various maternal characteristics and history through multivariate logistic analysis, and we compared the screening performance of our model with that recommended by National Institute of Health and Care Excellence (NICE) [8,9]. Our study showed that the performance of screening for GDM was superior when using a multivariate logistic model rather than treating each maternal factor as an independent screening test $[8,9]$. The significant contributors in our prediction model for GDM included maternal age, weight, height, racial origin, family history of diabetes, use of ovulation drugs, birth weight, and history of GDM in a previous pregnancy.

Twin pregnancies, compared to singletons, are at increased risk of pregnancy complications, including miscarriage, stillbirth, preterm birth, fetal growth restriction, and preeclampsia [10-12]. There is contradictory evidence concerning the incidence of GDM in twin pregnancies, with some studies reporting that this is higher than in singletons [13-18], while others found that the rates are similar $[17,18]$.

The objectives of this study were to: first, compare the rate of GDM in dichorionic and monochorionic twin pregnancies with that in singleton pregnancies and second, to modify 
our previously reported prediction model for GDM in singleton pregnancies [9] to include twin pregnancies.

\section{Materials and Methods}

\subsection{Study Population and Design}

The study population was derived from a prospective screening study on the early prediction of pregnancy complications in women attending for their routine first hospital pregnancy visit at King's College Hospital, London, between January 2010 and August 2020. At this visit, which is held at $11+0$ to $13+6$ weeks' gestation, we record maternal characteristics and medical history and perform an ultrasound scan for: first, determination of gestational age from the measurement of CRL [19]; second, diagnosis of major fetal abnormalities [20]; and third, measurement of fetal nuchal translucency thickness for assessment of risk for trisomies [21]. In the twin pregnancies, gestational age was determined from the CRL of the larger twin, and chorionicity was determined from the number of placentas and the presence or absence of the lambda sign at the inter-twin membrane-placental junction [22]. Each twin pregnancy was matched with 10 singleton pregnancies that were examined within 48 hours of the twin pregnancy. Written informed consent was obtained from the women agreeing to participate in the study, which was approved by the NHS Research Ethics Committee.

Details of maternal characteristics and the findings of the assessment at 11-13 weeks were recorded in our database. Patients were asked to complete a questionnaire on maternal age, racial origin (White, Black, South Asian, East Asian, or mixed), method of conception (natural or assisted conception by in-vitro fertilization or use of ovulation drugs), medical history (including pre-pregnancy diabetes mellitus type 1 or 2), family history of diabetes mellitus (first-, second- or third-degree relative with diabetes mellitus type 1 or 2), and obstetric history (parous or nulliparous with no previous pregnancies at or beyond 24 weeks; if parous, we recorded whether any of the previous pregnancies were complicated by GDM). The questionnaire was then reviewed by a doctor together with the patient. The maternal weight and height were measured, and the body mass index was calculated in $\mathrm{kg} / \mathrm{m}^{2}$.

Data on pregnancy outcome were obtained from the maternity computerized records or the general medical practitioners of the women and were also recorded in our database.

\subsection{Inclusion and Exclusion Criteria}

The inclusion criterion for this study was singleton or twin pregnancy delivering a phenotypically normal neonate at or after 28 weeks' gestation. We excluded pregnancies with pre-pregnancy diabetes mellitus type 1 or 2 and those ending in termination, miscarriage, or delivery before 28 weeks because they may not have had screening and diagnosis of GDM. We also excluded pregnancies with chromosomal abnormalities or major defects diagnosed prenatally or postnatally, those with twin reversed arterial perfusion (TRAP) sequence, or conjoined twins.

\subsection{Outcome Measure}

The outcome measure was GDM. The diagnosis of GDM was based on a 75-g oral glucose tolerance test (OGTT); the diagnostic criteria were fasting plasma glucose level $\geq 5.6 \mathrm{mmol} / \mathrm{L}$ and/or 2-h plasma glucose level $\geq 7.8 \mathrm{mmol} / \mathrm{L} \mathrm{[23].} \mathrm{The} \mathrm{screening} \mathrm{policies}$ leading to an OGTT changed over the years; from the beginning of the study until October 2018, all women had measurement of random plasma glucose at 24-28 weeks, and OGTT was carried out if the concentration was $>6.7 \mathrm{mmol} / \mathrm{L}$. From November 2018 onwards, there is a two-stage screening policy for GDM. First, women with any one risk factor (body mass index $>30 \mathrm{~kg} / \mathrm{m}^{2}$, previous birth of a macrosomic baby weighing $>4.5 \mathrm{~kg}$, previous GDM, first-degree relative with diabetes or persistent glucosuria) are offered measurement of glycosylated hemoglobin $(\mathrm{HbA} 1 \mathrm{c})$ at booking and, if the value is $\geq 5.7 \%$, then they have an OGTT, usually at around 12 weeks' gestation. Second, in all women 
at 26-28 weeks' gestation, plasma glucose level is measured $1-2 \mathrm{~h}$ after eating $\geq 50 \mathrm{~g}$ of carbohydrate, and if the concentration is $\geq 6.7 \mathrm{mmol} / \mathrm{L}$, then OGTT is carried out. During the whole study period, an OGTT is also performed if there is polyhydramnios or the fetus becomes macrosomic.

\subsection{Statistical Analysis}

Data were expressed as median (interquartile range (IQR)) for continuous variables and $n(\%)$ for categorical variables. Students $t$-test and $\chi^{2}$-square test or Fisher's exact test were used for comparing outcome groups for continuous and categorical data, respectively.

Using data on 75,161 singleton pregnancies, we developed an algorithm for the prediction of GDM in singleton pregnancies based on maternal characteristics and medical history [9]. Here, we use the linear predictor from this model as an offset for a further logistic regression model with terms for dichorionic and monochorionic twin pregnancies. This approach allowed us to both develop an extension for twins to our existing algorithm and to recalibrate the algorithm for singletons. An advantage to this approach over refitting the history model is that it allowed us to make good use of information gained from a much larger data set.

The statistical software package $\mathrm{R}$ was used for data analyses [24].

\section{Results}

\section{Study Population}

The inclusion criteria were fulfilled by 13,760 singleton and 1376 twin pregnancies; in the latter, 1111 were dichorionic, and 265 were monochorionic. GDM developed in $517(3.8 \%)$ of the singleton pregnancies and in $66(6.9 \%)$ of the dichorionic and $24(9.1 \%)$ of the monochorionic twin pregnancies.

The maternal and pregnancy characteristics of the GDM and non-GDM groups in singleton and twin pregnancies are shown in Table 1. In the GDM groups in both singleton and twin pregnancies, the women tended to be older, heavier, and shorter, and there was a higher proportion of Black, South Asian, and East Asian racial origin; conceptions with in-vitro fertilization; history of first- or second-degree relative with diabetes; and previous pregnancies complicated by GDM or higher birth weight of last neonates.

Table 1. Demographic and pregnancy characteristics of the study population.

\begin{tabular}{|c|c|c|c|c|c|c|}
\hline \multirow[b]{2}{*}{ Characteristic } & \multicolumn{3}{|c|}{ Singleton Pregnancies } & \multicolumn{3}{|c|}{ Twin Pregnancies } \\
\hline & $\begin{array}{l}\text { No GDM } \\
(n=13,243)\end{array}$ & GDM $(n=517)$ & $p$-Value & $\begin{array}{l}\text { No GDM } \\
(n=1286)\end{array}$ & GDM $(n=90)$ & $p$-Value \\
\hline Maternal age (years) & $32.5(28.7,35.7)$ & $34.0(30.5,37.1)$ & $<0.0001$ & $34.25(30.4,37.4)$ & $35.5(31.4,38.8)$ & 0.068 \\
\hline Maternal weight $(\mathrm{kg})$ & $66.5(59.4,76.3)$ & $76.1(65.0,91.0)$ & $<0.0001$ & $68.8(61.0,79.0)$ & $75.0(64.5,90.9)$ & 0.0005 \\
\hline Maternal height (cm) & $165(161,170)$ & $164(159,168)$ & $<0.0001$ & $166(162,170)$ & $164(158,169)$ & 0.003 \\
\hline $\begin{array}{l}\text { Body mass index } \\
\left(\mathrm{kg} / \mathrm{m}^{2}\right)\end{array}$ & $24.2(21.8,27.8)$ & $28.6(24.3,33.3)$ & $<0.0001$ & $24.6(22.1,28.2)$ & $28.0(24.6,33.3)$ & $<0.0001$ \\
\hline $\begin{array}{l}\text { Gestational age } \\
\text { (weeks) }\end{array}$ & $12.7(12.3,13.1)$ & $12.7(12.4,13.1)$ & 0.015 & $12.7(12.3,13.1)$ & $12.9(12.4,13.1)$ & 0.329 \\
\hline Racial origin & & & $<0.0001$ & & & 0.002 \\
\hline White & $9231(69.7 \%)$ & $276(53.4 \%)$ & & $892(69.4 \%)$ & $56(62.2 \%)$ & \\
\hline Black & $2735(20.7 \%)$ & $132(25.5 \%)$ & & $285(22.2 \%)$ & $21(23.3 \%)$ & \\
\hline South Asian & $550(4.2 \%)$ & $58(11.2 \%)$ & & $40(3.1 \%)$ & $10(11.1 \%)$ & \\
\hline East Asian & $252(1.9 \%)$ & $26(5.0 \%)$ & & $21(1.6 \%)$ & 0 & \\
\hline Mixed & $475(3.6 \%)$ & $25(4.8 \%)$ & & $48(3.7 \%)$ & $3(3.3 \%)$ & \\
\hline $\begin{array}{l}\text { Family history } \\
\text { of diabetes }\end{array}$ & & & $<0.0001$ & & & 0.018 \\
\hline 1st degree & $1525(11.5 \%)$ & $121(23.4 \%)$ & & $167(13.0 \%)$ & $19(21.1 \%)$ & \\
\hline 2nd degree & $1231(9.3 \%)$ & $56(10.8 \%)$ & & $141(11 \%)$ & $16(17.8 \%)$ & \\
\hline 3rd degree & $259(2.0 \%)$ & $11(2.1 \%)$ & & $19(1.5 \%)$ & $1(1.1 \%)$ & \\
\hline Method of conception & & & 0.387 & & & 0.107 \\
\hline
\end{tabular}


Table 1. Cont.

\begin{tabular}{|c|c|c|c|c|c|c|}
\hline \multirow[b]{2}{*}{ Characteristic } & \multicolumn{3}{|c|}{ Singleton Pregnancies } & \multicolumn{3}{|c|}{ Twin Pregnancies } \\
\hline & $\begin{array}{c}\text { No GDM } \\
(n=13,243)\end{array}$ & $\operatorname{GDM}(n=517)$ & $p$-Value & $\begin{array}{l}\text { No GDM } \\
(n=1286)\end{array}$ & GDM $(n=90)$ & $p$-Value \\
\hline Natural & $12,611(95.2 \%)$ & $486(94.0 \%)$ & & $886(68.90 \%)$ & $53(58.9 \%)$ & \\
\hline In-vitro fertilization & $530(4.0 \%)$ & $25(4.8 \%)$ & & $379(29.5 \%)$ & $36(40.0 \%)$ & \\
\hline Ovulation drugs & $102(0.8 \%)$ & $6(1.2 \%)$ & & $21(1.6 \%)$ & $1(1.1 \%)$ & \\
\hline Parity & & & $<0.0001$ & & & $<0.0001$ \\
\hline Nulliparous & $6532(49.3 \%)$ & $210(40.6 \%)$ & & $678(52.7 \%)$ & $46(51.1 \%)$ & \\
\hline Parous, previous GDM & $105(0.8 \%)$ & $82(15.9 \%)$ & & $9(0.7 \%)$ & $8(8.9 \%)$ & \\
\hline $\begin{array}{c}\text { Parous, no } \\
\text { previous GDM }\end{array}$ & $6606(49.9 \%)$ & $225(43.5 \%)$ & & $599(46.6 \%)$ & $36(40.0 \%)$ & \\
\hline $\begin{array}{l}\text { Birthweight of last } \\
\text { neonate }(\mathrm{g})\end{array}$ & $\begin{array}{c}3350 \\
(3015,3689)\end{array}$ & $\begin{array}{c}3433 \\
(3036,3860)\end{array}$ & 0.024 & $\begin{array}{c}3349 \\
(3000,3660)\end{array}$ & $\begin{array}{c}3405 \\
(3178,3750)\end{array}$ & 0.195 \\
\hline
\end{tabular}

The logistic regression model for the prediction of GDM from maternal characteristics and elements of medical history is shown in Table 2 and Figure 1. Confidence intervals are provided only for the estimates for twin pregnancies, as other coefficients are treated as fixed constants [9].

The performance of screening for GDM of the new model is summarized in Table 3. In singleton pregnancies, at $10 \%, 20 \%$, and $40 \%$ false-positive rates, the detection rates were $42.8 \%, 58.0 \%$, and $74.7 \%$, respectively. In twin pregnancies, at the same risk cut-offs corresponding to $10 \%, 20 \%$, and $40 \%$ false-positive rates in singletons, the respective false positive rates were $26.9 \%, 47.0 \%$, and $71.1 \%$, and the detection rates were $63.3 \%, 81.1 \%$, and $91.1 \%$.

Table 2. Logistic regression model for the prediction of gestational diabetes mellitus from maternal characteristics and elements of medical history. Confidence limits are provided only for the twin pregnancies because the odds ratio for the other terms are identical to those of our previous publication in singleton pregnancies [9].

\begin{tabular}{|c|c|c|c|}
\hline Term & Odds Ratio (95\% CI) & Coefficient & $p$-Value \\
\hline Intercept & - & -3.53042 & $<0.0001$ \\
\hline Twins: dischorionic & $1.3601(1.0213-1.8115)$ & 0.30759 & 0.035 \\
\hline Twins: monochorionic & $2.7771(1.7205-4.4823)$ & 1.02139 & $<0.0001$ \\
\hline Previous GDM & 50.44 & 3.92090 & \\
\hline Weight in kg—69 & 1.0208 & 0.02060 & \\
\hline \multicolumn{4}{|l|}{ Nulliparous or parous with no previous GDM } \\
\hline Parous: no previous GDM & 0.4545 & -0.78850 & \\
\hline Age in years-35 & 1.0841 & 0.08070 & \\
\hline Weight in $\mathrm{kg}-69$ & 1.0389 & 0.03810 & \\
\hline Height in $\mathrm{cm}-164$ & 0.9426 & -0.05910 & \\
\hline 1st-degree relative with $\mathrm{DM}$ & 2.5427 & 0.93320 & \\
\hline 2nd-degree relative with DM & 1.7984 & 0.58690 & \\
\hline Ovulation drugs & 1.6019 & 0.47120 & \\
\hline Black racial origin & 1.5780 & 0.45620 & \\
\hline East Asian racial origin & 2.9232 & 1.07270 & \\
\hline South Asian racial origin & 2.3165 & 0.84010 & \\
\hline Birth weight $\mathrm{z}$-score of previous pregnancy & 1.2520 & 0.22470 & \\
\hline
\end{tabular}




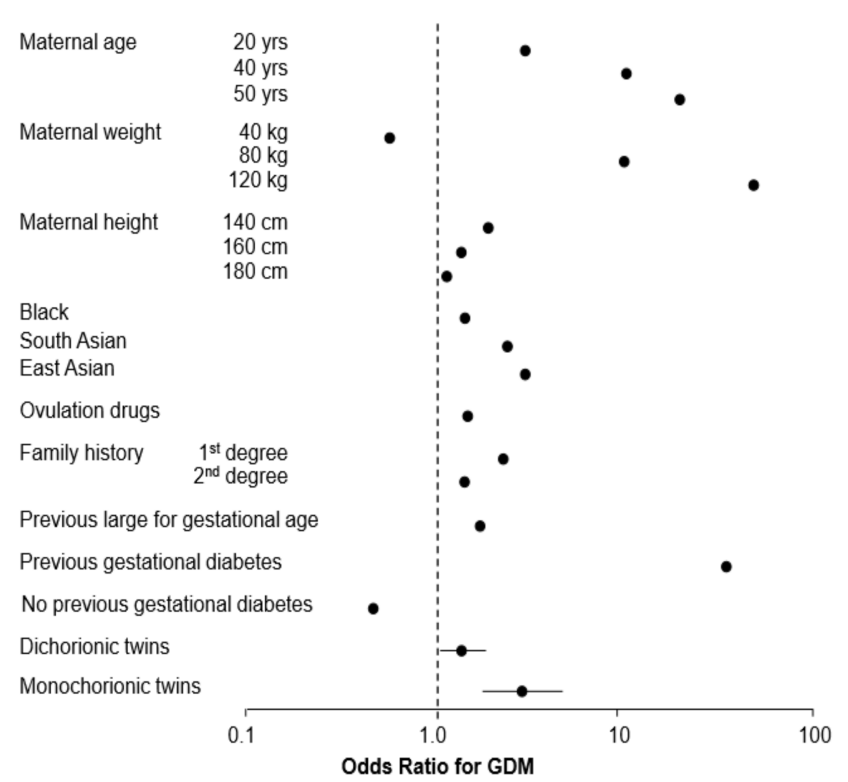

Figure 1. Odds ratio for gestational diabetes mellitus according to maternal factors and chorionicity. The odds ratio for each type of twin pregnancy refers to a woman who is 35 years old, $69 \mathrm{~kg}$ in weight, $164 \mathrm{~cm}$ in height, is of White racial origin, conceived naturally, has no family history of diabetes, and is nulliparous.

Table 3. Performance of screening for gestational diabetes mellitus in singleton and twin pregnancies.

\begin{tabular}{ccc}
\hline Pregnancy & FPR (\%) & DR (LCL-UCL) \% \\
\hline Singleton & 10.0 & $221 / 517 ; 42.8(38.4-47.1)$ \\
Twins & 26.9 & $57 / 90 ; 63.3(52.5-73.3)$ \\
Singleton & 20.0 & $300 / 517 ; 58.0(53.6-62.3)$ \\
Twins & 47.0 & $73 / 90 ; 81.1(71.5-88.6)$ \\
Singleton & 40.0 & $386 / 517 ; 74.7(70.7-78.4)$ \\
Twins & 71.1 & $82 / 90 ; 91.1(83.2-96.1)$ \\
\hline
\end{tabular}

FPR, false-positive rate; DR, detection rate; LCL, lower confidence limit; UCL, upper confidence limit.

\section{Discussion}

\subsection{Main Findings}

The study has demonstrated that the risk for GDM in twin pregnancies is higher than in singleton pregnancies after adjustment for elements of demographic characteristics and medical history that are known to be associated with GDM. The study also extended our previously described prediction model for GDM derived from the study of 75,161 singleton pregnancies [9] to also include dichorionic and monochorionic twins. In dichorionic and monochorionic twin pregnancies, the respective odds of GDM are 1.4 times and 2.8 times higher than in singleton pregnancies. In twin pregnancies, at the same risk cut-offs used for screening in singleton pregnancies, both the false-positive and detection rates are considerably higher.

In both singleton and twin pregnancies, the risk for GDM increases with increasing maternal age and weight and birth weight z-score of a baby in a previous pregnancy and is higher in women with a previous pregnancy complicated by GDM; in those with first- or second-degree relative with diabetes mellitus; in women of Black, East Asian and South Asian racial origin; and in pregnancies conceived through the use of ovulation induction drugs and is lower in parous women that did not develop GDM in a previous pregnancy. 


\subsection{Interpretation of Findings and Comparison with Results of Previous Studies}

Our finding that the incidence of GDM is higher in twin than singleton pregnancies is consistent with findings of four previous studies. Schwartz et al. [13] reported that the rate of GDM was $7.7 \%$ in 429 twin pregnancies and $4.1 \%$ in 29,644 singleton pregnancies. Rauh-Hain et al. [14] reported that the rate of GDM was 3.98\% in 533 twin pregnancies vs. 2.32 in 23,056 singleton pregnancies (odds ratio 2.2 after adjustment for age, body mass index, race, weight gain, blood pressure, parity, and smoking status). Weissman et al. [15] reported that the rate of GDM was $10.1 \%$ in 515 twin pregnancies vs. $2.9 \%$ in 12,382 singleton pregnancies. Hiersch et al. [16] analyzed the data of a large cohort of 266,942 singleton and 3901 twin pregancies and found a significantly higher risk for GDM in twins (relative risk of 1.13, after adjustment for age, parity, ethnicity, body mass index, and method of conception). In contrast, two studies reported that the incidence of GDM in twin pregnancies was not significantly different from that in singleton pregnancies. Buhling et al. [17] reported that the rate of GDM was 3.4\% in 89 twin pregnancies and $3.4 \%$ in 178 singleton pregnancies (matched for age, body mass index, parity, and ethnicity). Similarly, Morikawa et al. [18] reported that the rate of GDM was $9.3 \%$ in 86 twin pregnancies and $8.4 \%$ in 344 singleton pregnancies (matched for age and body mass index).

We found that the risk of GDM is higher in monochorionic than in dichorionic twin pregnancies. This finding is consistent with the results of a previous study in twin pregnancies [25]. A possible explanation for this finding is that in monochorionic twin pregnancies, serum plasma protein-A (PAPP-A) is lower than in dichorionic twins [26]. We previously reported that there is an association between low serum PAPP-A at 11-13 weeks' gestation and both type 2 diabetes mellitus and GDM [27-29]. PAPPA is a metalloprotease secreted by the human placenta that modulates insulin-like growth factor (IGF) bioavailability through proteolysis of IGF-binding proteins (IGFBPs) 2, 4, and 5. There is evidence that low concentrations of PAPPA result in impaired proteolysis of adipose tissue IGFBPs, which are up-regulated in adipose depots during pregnancy [30]. In turn, IGF signaling decreases, impairing pregnancy-induced increases in adipocyte number and size as well as tissue vascularization. Inadequate adipose tissue adaptation leads to enhanced insulin resistance and impaired glucose tolerance.

The new model predicts $42.8 \%, 58.0 \%$, and $74.7 \%$ of GDM in singleton pregnancies at $10 \%, 20 \%$, and $40 \%$ false-positive rates, respectively. These detection rates are lower than the respective values of $55 \%, 68 \%$, and $84 \%$ achieved in our previous publication [9]. The most likely explanation for such a drop is that the inclusion criteria for screening for GDM has recently become less stringent so that a higher proportion of the population is now found to be screen positive; consequently, the false-positive rate is higher.

\subsection{Strengths and Limitations}

The study has major strengths, which include a large sample size, a systematic approach of obtaining obstetric and medical history, and measurement of maternal weight and height. Moreover, we modified a previously reported multivariate logistic model derived from the study of 75,161 singleton pregnancies to include prediction of GDM in twin pregnancies, and we matched each twin pregnancy with 10 singleton pregnancies examined within two days from the twins to minimize the potential risk of bias arising from possible changes of screening policies over the long study period of 10 years. A limitation of the study narrates to the method of detecting pregnancies affected by GDM. Universal testing with a diagnostic OGTT was not performed in all pregnancies, as recommended by the International Association of Diabetes and Pregnancy Study Groups [7], but only in a subgroup with either risk factors for GDM [8] or abnormal results of a random blood glucose level at 24-28 weeks' gestation. Consequently, it is likely that our non-GDM group contained women who had undiagnosed GDM, and therefore, the screening performance of our method was overestimated. 


\section{Conclusions}

In this study, we extended our logistic regression model for first-trimester prediction of GDM from maternal characteristics and medical history to include terms for dichorionic and monochorionic twin pregnancies. The risk of GDM was higher in monochorionic than in dichorionic twin pregnancies, and this could be the consequence of inadequate adipose tissue adaptation, enhanced insulin resistance, and impaired glucose tolerance due to lower serum PAPP-A.

Author Contributions: Conceptualization, K.H.N. and A.S.; methodology, K.H.N. and A.S.; supervision, K.H.N.; writing-original draft preparation, K.H.N. and O.B.; resources, A.S., O.B., T.E., and A.V.; formal analysis, A.W. All authors have read and agreed to the published version of the manuscript.

Funding: This research was supported by grants from the Fetal Medicine Foundation (UK Charity No: 1037116). This body had no involvement in the study design; in the collection, analysis and interpretation of data; in the writing of the report; and in the decision to submit the article for publication.

Institutional Review Board Statement: The study was conducted according to the guidelines of the Declaration of Helsinki and approved by the NHS Research Ethics Committee (REC reference: 02-03-033 on 11 March 2003).

Informed Consent Statement: Informed consent was obtained from all subjects involved in the study.

Data Availability Statement: Research data are not shared.

Conflicts of Interest: The authors report no conflict of interest.

\section{References}

1. Casey, B.M.; Lucas, M.J.; Mclntire, D.D.; Leveno, K.J. Pregnancy Outcomes in Women with Gestational Diabetes Compared with the General Obstetric Population. Obstet. Gynecol. 1997, 90, 869-873. [CrossRef]

2. Crowther, C.A.; Hiller, J.E.; Moss, J.R.; McPhee, A.J.; Jeffries, W.S.; Robinson, J.S. Effect of treatment of gestational diabetes on pregnancy outcomes. Australian Carbohydrate Intolerance Study in Pregnant Women (ACHOIS) Trial Group. N. Engl. J. Med. 2005, 352, 2477-2486. [CrossRef] [PubMed]

3. Clausen, T.D.; Mathiesen, E.; Hansen, T.; Pedersen, O.; Jensen, D.M.; Lauenborg, J.; Damm, P. High Prevalence of Type 2 Diabetes and Pre-Diabetes in Adult Offspring of Women With Gestational Diabetes Mellitus or Type 1 Diabetes: The role of intrauterine hyperglycemia. Diabetes Care 2007, 31, 340-346. [CrossRef]

4. HAPO Study Cooperative Research Group; Metzger, B.E.; Lowe, L.P.; Dyer, A.R.; Trimble, E.R.; Chaovarindr, U.; Coustan, D.R.; Hadden, D.R.; McCance, D.R.; Hod, M.; et al. Hyperglycemia and adverse pregnancy outcomes. N. Engl. J. Med. 2008, 358, 1991-2002. [PubMed]

5. Feig, D.S.; Zinman, B.; Wang, X.; Hux, J.E. Risk of development of diabetes mellitus after diagnosis of gestational diabetes. CMAJ 2008, 179, 229-234. [CrossRef]

6. Bellamy, L.; Casas, J.-P.; Hingorani, A.; Williams, D. Type 2 diabetes mellitus after gestational diabetes: A systematic review and meta-analysis. Lancet 2009, 373, 1773-1779. [CrossRef]

7. Metzger, B.E.; Gabbe, S.G.; Persson, B.; Buchanan, T.A.; Catalano, P.A.; Damm, P.; Dyer, A.R.; Leiva, A.D.; Hod, M.; Kitzmiler, J.L.; et al. International Association of Diabetes and Pregnancy Study Groups recommendations on the diagnosis and classification of hyperglycemia in pregnancy. Diabetes Care 2010, 33, 676-682. [CrossRef]

8. National Collaborating Centre for Women's and Children's Health. Diabetes in Pregnancy: Management of Diabetes and ITS Complications from Pre-Conception to the Postnatal Period. 2008. Available online: www.nice.org.uk/CG063fullguideline (accessed on 26 April 2021).

9. Syngelaki, A.; Pastides, A.; Kotecha, R.; Wright, A.; Akolekar, R.; Nicolaides, K.H. First-Trimester Screening for Gestational Diabetes Mellitus Based on Maternal Characteristics and History. Fetal Diagn. Ther. 2014, 38, 14-21. [CrossRef]

10. Litwinska, E.; Syngelaki, A.; Cimpoca, B.; Frei, L.; Nicolaides, K.H. Outcome of twin pregnancy with two live fetuses at 11-13 weeks' gestation. Ultrasound Obstet. Gynecol. 2019, 55, 32-38. [CrossRef] [PubMed]

11. Francisco, C.; Wright, D.; Benkő, Z.; Syngelaki, A.; Nicolaides, K. Hidden high rate of pre-eclampsia in twin compared with singleton pregnancy. Ultrasound Obstet. Gynecol. 2017, 50, 88-92. [CrossRef]

12. Benkő, Z.; Wright, A.; Rehal, A.; Cimpoca, B.; Syngelaki, A.; Delgado, J.L.; Tsokaki, T.; De Alvarado, M.; Vojtassakova, D.; Ntalianis, K.M.; et al. Prediction of pre-eclampsia in twin pregnancy by maternal factors and biomarkers at 11-13 weeks' gestation: Data from EVENTS trial. Ultrasound Obstet. Gynecol. 2020, 57, 257-265. [CrossRef] 
13. Schwartz, D.B.; Daoud, Y.; Zazula, P.; Goyert, G.; Bronsteen, R.; Wright, D.; Copes, J. Gestational diabetes mellitus: Metabolic and blood glucose parameters in singleton versus twin pregnancies. Am. J. Obstet. Gynecol. 1999, 181, 912-914. [CrossRef]

14. Rauh-Hain, J.A.; Rana, S.; Tamez, H.; Wang, A.; Cohen, B.; Cohen, A.; Brown, F.; Ecker, J.L.; Karumanchi, S.A.; Thadhani, R. Risk for developing gestational diabetes in women with twin pregnancies. J. Matern. Fetal Neonatal Med. 2009, 22, 293-299. [CrossRef]

15. Weissman, A.; Drugan, A. Glucose tolerance in singleton, twin and triplet pregnancies. J. Perinat. Med. 2016, 44, 893-897. [CrossRef]

16. Hiersch, L.; Berger, H.; Okby, R.; Ray, J.G.; Geary, M.; Mcdonald, S.D.; Murry-Davis, B.; Riddell, C.; Halperin, I.; Hasan, H.; et al. Incidence and risk factors for gestational diabetes mellitus in twin versus singleton pregnancies. Arch Gynecol Obstet. 2018, 29, 579-587. [CrossRef]

17. Buhling, K.J.; Henrich, W.; Starr, E.; Lubke, M.; Bertram, S.; Siebert, G.; Dudenhausen, J.W. Risk for gestational diabetes and hypertension for women with twin pregnancy compared to singleton pregnancy. Arch. Gynecol. Obstet. 2003, 269, 33-36. [CrossRef] [PubMed]

18. Morikawa, M.; Yamada, T.; Akaishi, R.; Kojima, T.; Nishida, R.; Koyama, T.; Cho, K.; Minakami, H. Prevalence of hyperglycaemia in singleton versus twin pregnancy. Diabetes Metab. Res. Rev. 2014, 31, 198-203. [CrossRef] [PubMed]

19. Robinson, H.P.; Fleming, J.E.E. A Critical Evaluation of Sonar Crown-Rump Length Measurements. Br. J. Obstet. Gynaecol. 1975, 82, 702-710. [CrossRef] [PubMed]

20. Syngelaki, A.; Cimpoca, B.; Litwinska, E.; Akolekar, R.; Nicolaides, K.H. Diagnosis of non-chromosomal fetal abnormalities in twin pregnancies at routine ultrasound examination at 11-13 weeks' gestation. Ultrasound Obs. Gynecol. 2020, 55, 474-481. [CrossRef] [PubMed]

21. Snijders, R.; Noble, P.; Sebire, N.; Souka, A.; Nicolaides, K. UK multicentre project on assessment of risk of trisomy 21 by maternal age and fetal nuchal-translucency thickness at 10-14 weeks of gestation. Fetal Medicine Foundation First Trimester Screening Group Lancet 1998, 352, 343-346. [CrossRef]

22. Sepulveda, W.; Sebire, N.J.; Hughes, K.; Odibo, A.; Nicolaides, K. The lambda sign at 10-14 weeks of gestation as a predictor of chorionicity in twin pregnancies. Ultrasound Obstet. Gynecol. 1996, 7, 421-423. [CrossRef] [PubMed]

23. World Health Organization. Department of Noncommunicable Disease Surveillance: Definition, diagnosis and classification of diabetes mellitus and its complications. In Report of a WHO Consultation. Part 1. Diagnosis and Classification of Diabetes Mellitus; World Health Organization: Geneva, Switzerland, 1999.

24. R Core Team. R: A Language and Environment for Statistical Computing; R Foundation for Statistical Computing: Vienna, Austria, 2017; Available online: https:/ / www.R-project.org/ (accessed on 20 June 2021).

25. Feng, B.; Zhai, J.; Cai, Y. Effect of twin pregnancy chorionic properties on maternal and fetal outcomes. Taiwan J. Obstet. Gynecol. 2018, 57, 351-354. [CrossRef] [PubMed]

26. Madsen, H.N.; Ball, S.; Wright, D.; Tørring, N.; Petersen, O.B.; Nicolaides, K.; Spencer, K. A reassessment of biochemical marker distributions in trisomy 21-affected and unaffected twin pregnancies in the first trimester. Ultrasound Obstet. Gynecol. 2010, 37, 38-47. [CrossRef] [PubMed]

27. Savvidou, M.D.; Syngelaki, A.; Muhaisen, M.; Emelyanenko, E.; Nicolaides, K.H. First trimester maternal serum free beta-human chorionic gonadotropin and pregnancy-associated plasma protein A in pregnancies complicated by diabetes mellitus. BJOG 2012, 119, 410-416. [CrossRef] [PubMed]

28. Ong, C.Y.T.; Liao, A.W.; Spencer, K.; Munim, S.; Nicolaides, K. First trimester maternal serum free beta human chorionic gonadotrophin and pregnancy associated plasma protein A as predictors of pregnancy complications. BJOG 2000, 107, 1265-1270. [CrossRef]

29. Syngelaki, A.; Kotecha, R.; Pastides, A.; Wright, A.; Nicolaides, K.H. First-trimester biochemical markers of placentation in screening for gestational diabetes mellitus. Metabolism 2015, 64, 1485-1489. [CrossRef] [PubMed]

30. Rojas-Rodriguez, R.; Ziegler, R.; DeSouza, T.; Majid, S.; Madore, A.S.; Amir, N.; Pace, V.A.; Nachreiner, D.; Alfego, D.; Mathew, J.; et al. PAPPA-mediated adipose tissue remodeling mitigates insulin resistance and protects against gestational diabetes in mice and humans. Sci. Transl. Med. 2020, 12, eaay4145. [CrossRef] [PubMed] 